\title{
Time-dependent network analysis reveals molecular targets underlying the development of diet-induced obesity and non-alcoholic steatohepatitis
}

\author{
Hea-Young Oh $\cdot$ Su-kyung Shin $\cdot$ Hyoung-Sam Heo $\cdot$ Ji-Sook Ahn $\cdot$ Eun-Young Kwon $\cdot$ \\ Jung Han Yoon Park $\cdot$ Yun-young Cho $\cdot$ Hae-Jin Park $\cdot$ Mi-Kyung Lee $\cdot$ Eun Jung Kim • \\ Un-Ju Jung $\cdot$ Robin A. McGregor $\cdot$ Cheol-Goo Hur $\cdot$ Myung-Sook Choi
}

Received: 6 June 2012/ Accepted: 26 September 2012/Published online: 13 November 2012

(c) Springer-Verlag Berlin Heidelberg 2012

\begin{abstract}
Prolonged high-fat diet leads to the development of obesity and multiple comorbidities including nonalcoholic steatohepatitis (NASH), but the underlying molecular basis is not fully understood. We combine molecular networks and time course gene expression profiles to reveal the dynamic changes in molecular networks underlying diet-induced obesity and NASH. We also identify hub genes associated with the development of NASH. Core diet-induced obesity networks were constructed using Ingenuity pathway analysis (IPA) based on 332 high-fat diet responsive genes identified in liver by time course microarray analysis (8 time points over 24 weeks) of high-fat diet-fed mice compared to normal diet-fed mice. IPA identified five core diet-induced obesity
\end{abstract}

Hea-Young Oh and Su-kyung Shin contributed equally.

Electronic supplementary material The online version of this article (doi:10.1007/s12263-012-0322-6) contains supplementary material, which is available to authorized users.

H.-Y. Oh · H.-S. Heo · J.-S. Ahn · C.-G. Hur ( $\bowtie)$

Division of Biosystems Research, Green Bio Research Center,

Korea Research Institute of Bioscience and Biotechnology

(KRIBB), 111 Gwahangno, Yuseong-gu, Daejeon 305-806,

Republic of Korea

e-mail: hurlee@kribb.re.kr

S. Shin · E.-Y. Kwon · Y. Cho · H.-J. Park · U.-J. Jung ·

R. A. McGregor - M.-S. Choi ( $\square)$

Department of Food Science and Nutrition,

Center for Food and Nutritional Genomics Research,

Kyungpook National University, 1370 Sank-Yuk Dong Puk-Ku,

Daegu 702-701, Republic of Korea

e-mail: mschoi@knu.ac.kr

J.-S. Ahn

Department of Bioinformatics, University of Science

and Technology (UST), Daejeon, Republic of Korea networks with time-dependent gene expression changes in liver. These networks were associated with cell-to-cell signaling and interaction (Network 1), lipid metabolism (Network 2), hepatic system disease (Network 3 and 5), and inflammatory response (Network 4). When we merged these core diet-induced obesity networks, Tlr2, Cd14, and Ccnd1 emerged as hub genes associated with both liver steatosis and inflammation and were altered in a timedependent manner. Further, protein-protein interaction network analysis revealed Tlr2, Cd14, and Ccnd1 were interrelated through the ErbB/insulin signaling pathway. Dynamic changes occur in molecular networks underlying diet-induced obesity. Tlr2, Cd14, and Ccnd1 appear to be hub genes integrating molecular interactions associated with the development of NASH. Therapeutics targeting hub genes and core diet-induced obesity networks may help ameliorate diet-induced obesity and NASH.

\author{
J. H. Y. Park \\ Department of Food Science and Nutrition, \\ College of Natural Sciences, Hallym University, \\ Chuncheon 200-702, Republic of Korea \\ M.-K. Lee \\ Department of Food Science and Nutrition, Sunchon National \\ University, Sunchon, Republic of Korea \\ E. J. Kim \\ Department of Food Science and Nutrition, \\ Daegu Catholic University, Gyeongsan, Republic of Korea
}


Keywords Transcription - Cirrhosis - Hepatic steatosis . Microarray · Network · Obesity

\section{Introduction}

The global prevalence of overweight and obesity has increased every decade, with an estimated 1.46 billion adults overweight, 205 million men obese, and 297 million women obese (Finucane et al. 2011). Obesity is associated with increased risk of multiple chronic conditions included diabetes, cardiovascular diseases, stroke, fatty liver, non-alcoholic steatohepatitis (NASH), and other comorbidities (Guh et al. 2009; Strazzullo et al. 2010). Recent reports indicate current obesity trends will continue to cause substantial morbidity, mortality, and economic burden over the coming decades (Wang et al. 2011). Therefore, there is considerable interest in identifying molecular targets underlying the development of obesity and related comorbidities, which will facilitate the development of novel therapeutics.

Disease phenotypes are the result of complex molecular interactions between genes and proteins. The development of systems biology approaches has allowed candidate disease genes identified through genome-wide microarray studies to be considered within larger integrated molecular networks based on gene-gene interactions and proteinprotein interactions (Ideker and Sharan 2008). Many studies have reported differences in lipid metabolism, inflammation, and insulin resistance-related genes based on cross-sectional microarray analysis of various murine dietinduced obesity models (Gregoire et al. 2002; Kim et al. 2004; Matsuzawa et al. 2007; Radonjic et al. 2009; Fraulob et al. 2010; Kleemann et al. 2010). Animal models of dietinduced obesity are characterized by hepatic steatosis, an early event in non-alcoholic fatty liver disease (NAFLD) and non-alcoholic steatohepatitis (NASH) development (Hebbard and George 2011). However, network studies of obesity and related comorbidities such as NASH have predominately been limited to static network analysis. In morbidly obese subjects with NAFLD undergoing bariatric surgery network analysis of genes differentially expressed compared to controls identified four primary gene networks associated with NAFLD including cell death, immunological disease, cellular movement, and lipid metabolism (Gawrieh et al. 2010). A more recent study reported gene expression differences in morbidly obese patients even with histologically normal liver and no overt sign of steatosis compared to controls (Bertola et al. 2010), indicating early transcriptional biomarkers may precede development of hepatic steatosis and non-alcoholic steatohepatitis (NASH). Unfortunately, these studies do not consider the dynamic changes in gene expression, which we know occur during the pathogenesis of diet-induced obesity and the development of obesity-related comorbidities (Radonjic et al. 2009; Do et al. 2011).

To date, only two microarray studies have considered the time course of global transcriptional changes in liver during the development of obesity using animal models (Radonjic et al. 2009; Do et al. 2011). In ApoE3Leden, mice fed a high-fat diet and sacrificed at multiple time points over 16 weeks, the transition from an inflammatory to a steatosis transcriptional program emerges as a principal signature of the hepatic adaptation to excess dietary fat; however, these changes may also be attributable to aging (Radonjic et al. 2009). In C57BL/6 J, mice fed a high-fat diet over 24 weeks, time course microarrays and metabolic analysis reveal evidence of compensatory transcriptional and metabolic changes in liver to resist the increase in energy balance, but adaptation appears to be disrupted later during the development of diet-induced obesity (Do et al. 2011). Interestingly, evidence from morbidly obese patients undergoing bariatric surgery indicates while some differentially expressed genes may plausibly cause NASH, some hepatic genes appear to play a hepatoprotective role and are part of a positive adaptation which may slow NASH development (Baranova et al. 2007). Taken together, these studies highlight the necessity of time-dependent dietinduced obesity models to improve our understanding of the dynamic changes occurring in molecular networks underlying the development of obesity and NASH.

Time-dependent network approaches have been applied previously to elucidate the molecular interactions underlying the systemic inflammatory response in human leukocytes (Calvano et al. 2005). However, to date, the long-term dynamic molecular network underlying the development of diet-induced obesity in liver or dietinduced non-alcoholic steatohepatitis has not been previously reported. Accordingly, the aim of this study was to determine the core diet-induced obesity networks altered in a time-dependent manner in high-fat diet-fed C57BL/6 J mice compared to age-matched normal diet-fed controls. Furthermore, we identified hub genes in diet-induced obesity and an underlying protein-protein interaction network, which may cause the development of NASH.

\section{Materials and methods}

Experimental design, animals, and diets

A time course experimental design was used, based on a well-characterized long-term diet-induced obesity model, which included normal diet and age-dependent controls as previously reported (Do et al. 2011). Three hundred and 
sixty male inbred C57BL/6 J mice were obtained from the Jackson Laboratory (Bar Harbor, ME) at 4 weeks of age. All the mice were individually housed under a constant temperature $\left(24^{\circ} \mathrm{C}\right)$ and 12-h light/dark cycle, fed the AIN-76 semi-purified diet for 1 week acclimation period after arrival, and then randomly divided into an ND and an HFD group, with 18 mice per group. After the acclimation period, the HFD group was fed the AIN-76 semi-purified diet consisting of $20 \%$ fat and $1 \%$ cholesterol and ND group was fed the AIN-76 diet. (American Institute of Nutrition 1977). Mice were anaesthetized and killed at 0, 2 , $4,6,8,12,16,20$, and 24 weeks. The liver tissue was then removed, rinsed, weighed, immediately frozen in liquid nitrogen, and stored at $-70{ }^{\circ} \mathrm{C}$ until further analysis. The study protocol was approved by the Ethics Committee for animal studies at Kyungpook National University, Republic of Korea.

Histopathological analysis of hepatic fibrosis

Hepatic tissue was removed from each mouse and cleaned free of connective tissues. Samples were then fixed in $10 \%$ $(\mathrm{v} / \mathrm{v})$ paraformaldehyde/PBS, embedded in paraffin, and sliced into $3-5-\mu \mathrm{m}$ thick sections. Sections were stained by Masson's trichrome staining to visualize the connective tissue with collagen fibers. The stained area was viewed using a microscope at a magnification of $200 \times$.

\section{Microarray analysis}

Total RNA was amplified and purified using the Ambion Illumina RNA amplification kit (Ambion, USA) to yield biotinylated cRNA. A total of $750 \mathrm{ng}$ biotinylated cRNA per sample was hybridized to Illumina Mouse WG-6 v2 Expression Beadchips (Illumina, USA) for $16 \mathrm{~h}$ at $58^{\circ} \mathrm{C}$ according to the manufacturer's instructions. Hybridized arrays were washed and stained with Amersham fluorolink streptavidinCy3 (GE Healthcare Bio-Science, UK) following the standard protocol in the bead array manual. The quality of hybridization and overall chip performance were determined by visual inspection of both internal quality controls and the raw scanned data in the Illumina BeadStudio software. Probe signal intensities significantly higher than background intensities were determined (detection $p$ value $<0.05$ ), but probe signal data were not filtered to preserve probes with low expression at different time points. Probe signal intensities were quantile normalized and log-transformed. Microarray analysis was performed in the ArrayAssist ${ }^{\circledR}$ software (Stratagene, USA), Bioconductor and R programing language. LIMMA was used to determine significant differentially expressed genes (HFD responsive genes) between HFD- and ND-fed mice at each time point based on FDR $<5 \%$, Benjamin and Hochberg-adjusted $p$ value $<0.05$, and log-fold change $>1$ (Smyth 2005).

Core diet-induced obesity network analysis

Three hundred and thirty-two high-fat diet responsive genes were used for core network analysis identified previously (Do et al. 2011). General study flow for the network analysis is illustrated in Fig. 1. To examine the interactions between the high-fat responsive genes, we used Ingenuity pathway analysis (Ingenuity ${ }^{\circledR}$ Systems, www.ingenuity.com, IPA version: 8.8 (2010), Content version: 3204 (2010)). IPA allows the identification of network interactions and pathway interactions between genes based on an extensive manually curated database of published gene interactions. We uploaded the ProbeID and the associated expression value from the microarray data into IPA. Each probeID was mapped to its corresponding gene object in the Ingenuity pathway knowledge base. These genes, called focus genes, were overlaid onto a global molecular network based on Ingenuity knowledge database. Networks of these focus genes were then algorithmically generated based on their types of interactions (direct and/or indirect). Scores were generated (based on Fisher's test) to rank networks according to how relevant they are to the genes in the input dataset. The score takes into account the number of focus genes from our lists in the network, and the size of the network to approximate how relevant this network is to the original list of focus genes. The network is then presented as a graph indicating the molecular relationships between genes/gene products. Genes or gene products are represented as nodes, and the biological relationships between nodes are represented as an edge (line). The connectivity of genes (nodes) is based on the data in the IPA knowledge base, which is a large repository of genephenotype associations, molecular interactions, chemical knowledge, and regulatory events, manually curated from scientific publications. The node color indicates the degree of up-regulation (red) or down-regulation (green). Nodes are displayed using various shapes that represent the functional class of gene product. Edges are displayed with various labels that describe the nature of the relationship between the nodes. Time course microarray data were mapped onto the core networks to explore the dynamic changes during the development of diet-induced obesity.

The biological functions and/or diseases that were significantly associated with the genes in the core networks were identified by functional analysis based on the Ingenuity's knowledge base. The right-tailed Fisher's exact test was used to calculate a $p$ value determining the probability that each biological function and/or disease assigned to a specific core diet-induced obesity network was due to chance alone. 
Fig. 1 A study flow chart showing hepatic network analysis based on time course microarrays $(2,4,6,8,12,16$, 20, 24 weeks) of liver from long-term high-fat diet-fed C57BL/6 J mice

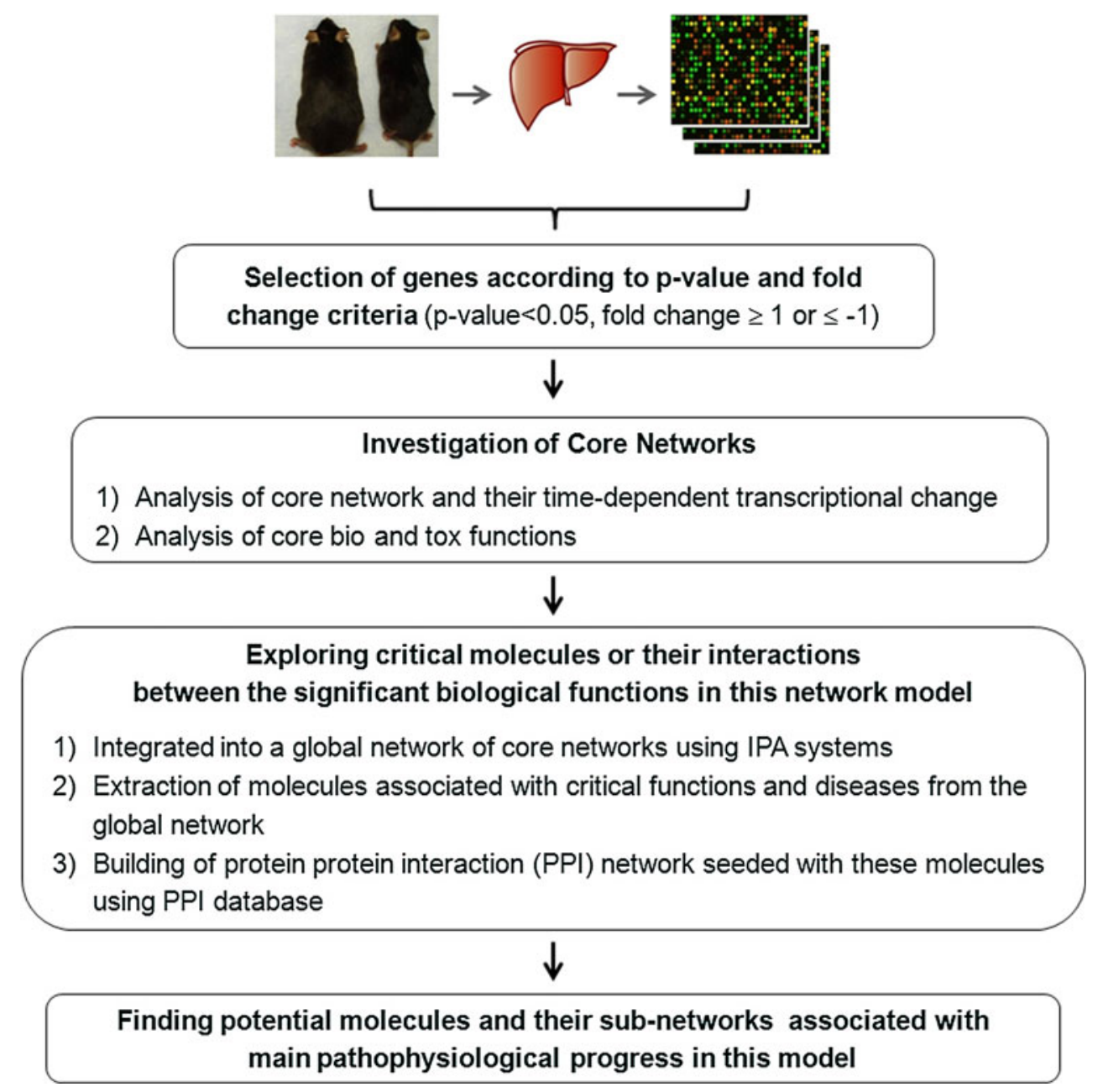

Hepatic steatosis protein-protein interaction network analysis

Core networks were merged and overlayed with related "functions and diseases" to determine genes associated with two specific hepatic responses (immune/inflammatory and liver steatosis) according to the IPA knowledge base. Those genes associated with both liver steatosis and inflammation were used to build a protein-protein interaction (PPI) network using the STRING database which contains interactions between 2.5 million proteins from 630 organisms and is widely used to investigate protein regulatory networks in disease (Jensen et al. 2009). To enrich this PPI network, additional genes that are potentially associated with these overlapped genes were included through a broad mining of the String database and differentially expressed genes identified in our time-dependent diet-induced obesity model. The molecular interaction repository MiMI, which integrates data from multiple sources, was used to map protein to functional genes (Gao et al. 2009). Cytoscape was used to visual protein-protein interaction networks, which shows nodes and edges as proteins and interactions between two proteins, respectively (Shannon et al. 2003). A human protein-protein interaction network was also built with human orthologs of the mouse genes associated with both liver steatosis and inflammation in our diet-induced obesity model. Orthology between human and mouse was determined by searching ortholog genes via NCBI.

\section{Results}

Time-dependent changes in hepatic fibrosis and metabolic biomarkers in diet-induced obesity

To determine the time course of fibrosis during the development of diet-induced obesity, we performed Masson's trichrome staining of livers from the HFD group compared with the ND group at $0,2,4,6,8,12,16,20$, and 24 weeks. The HFD-fed mice displayed signs of fibrosis from week 16 and accumulation of collagen surrounding the central venule (Fig. 2). However, fibrosis and collagen accumulation were more visible at week 24 in the HFD-fed 

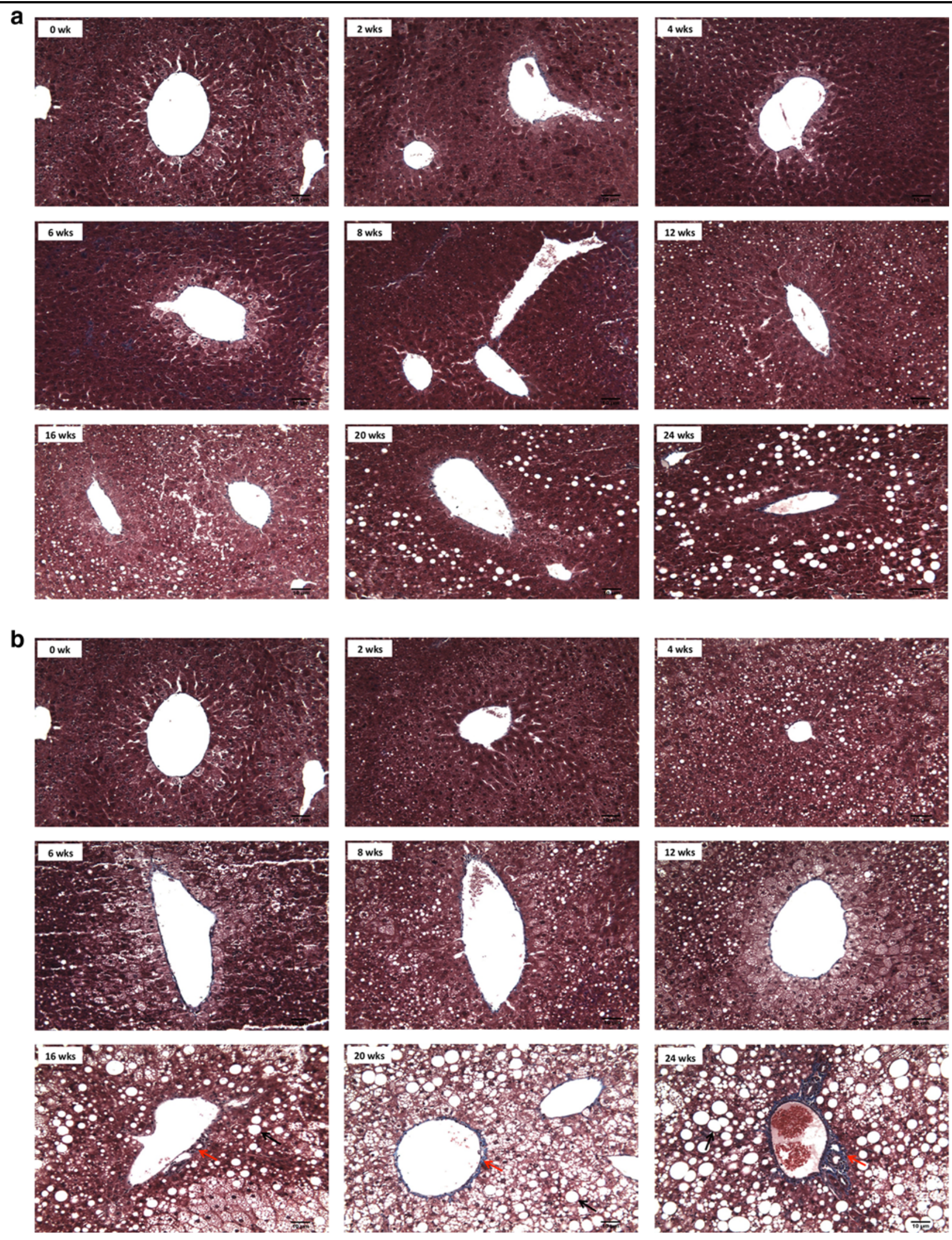

Fig. 2 Fibrotic changes of liver sections in time-dependent manner (Masson trichrome stain, original magnification $\times 200$ ). a Normal diet groups, b High-fat diet groups. Red arrow fibrosis, black arrow lipid droplet (color figure online) 
Table 1 Phenotype biomarkers of high-fat-fed mice

\begin{tabular}{|c|c|c|c|}
\hline \multirow[t]{2}{*}{ Biomarkers } & \multirow{2}{*}{$\begin{array}{l}0 \text { week } \\
\text { Baseline }\end{array}$} & \multicolumn{2}{|l|}{24 weeks } \\
\hline & & ND & HFD \\
\hline Body weight gain (g) & $18.02 \pm 0.39$ & $33.43 \pm 0.86$ & $45.92 \pm 0.60 * * *$ \\
\hline Total WAT (g/100 g B.W.) & $1.70 \pm 0.09$ & $13.04 \pm 0.72$ & $22.55 \pm 0.42 * * *$ \\
\hline Liver weight (g/100 g B.W.) & $4.32 \pm 0.06$ & $3.78 \pm 0.11$ & $6.97 \pm 0.18 * * *$ \\
\hline Fasting blood glucose (mg/dL) & $80.83 \pm 4.69$ & $114.38 \pm 5.39$ & $133.00 \pm 2.98^{* *}$ \\
\hline Hepatic cholesterol (mmol/g Liver) & $0.48 \pm 0.03$ & $2.63 \pm 0.28$ & $9.07 \pm 1.07 * * *$ \\
\hline Hepatic FFA (mmol/g Liver) & $1.35 \pm 0.16$ & $2.55 \pm 0.20$ & $7.43 \pm 0.46^{* * *}$ \\
\hline Hepatic triglycerides (mg/g Liver) & $6.27 \pm 0.49$ & $19.49 \pm 1.20$ & $37.70 \pm 2.67 * * *$ \\
\hline Plasma total cholesterol $(\mathrm{mmol} / \mathrm{L})$ & $1.70 \pm 0.06$ & $4.38 \pm 0.13$ & $10.02 \pm 0.28 * * *$ \\
\hline Plasma LDL-C (mmol/L) & $1.20 \pm 0.01$ & $3.37 \pm 0.16$ & $8.27 \pm 0.27 * * *$ \\
\hline Plasma HDL-C (mmol/L) & $0.24 \pm 0.005$ & $0.91 \pm 0.04$ & $1.62 \pm 0.06 * * *$ \\
\hline Atherogenic index (A.U) & $5.83 \pm 0.07$ & $3.85 \pm 0.25$ & $5.95 \pm 0.33 * * *$ \\
\hline
\end{tabular}

Data are Mean $\pm \mathrm{SE}$

$N D$ normal diet (AIN-76), HFD high-fat diet (20\% fat, $1 \%$ cholesterol), $B W$ body weight, FFA free fatty acid, Total WAT total white adipose tissue $=$ epididymal fat + Perirenal fat + Retro-peritoneum fat + Mesentery fat + Subcutaneous fat + Interscapular WAT

Values are significantly different from the ND group according to Student's $t$ test: * $p<0.05 ; * * p<0.01 ; * * * p<0.001$

mice. We also observed the C57BL/6 J mice used in this study developed signs of fibrosis as a result of aging even when fed a normal diet, although fibrosis was not morphologically detectable until week 16 in the ND group and was much less prominent than the HFD group at week 16 (Fig. 2). Time-dependent changes in blood glucose, plasma lipids, hepatic lipids, and body fat mass in this diet-induced obesity model have been previously reported (Do et al. 2011) and are shown in Table 1.

\section{Core diet-induced obesity networks}

Three hundred and thirty-two high-fat responsive genes were used for the core network analysis in IPA to identify significant networks and functions underlying diet-induced obesity. The top 5 networks exhibiting the highest scores and their associated network functions are described in Table 2 and Fig. 3. The top biological and toxicological functions associated with these core diet-induced obesity

Table 2 Top 5 core diet-induced obesity networks generated with IPA, based on high-fat diet responsive genes identified in long-term high-fat diet-fed C57BL/6 J mice

\begin{tabular}{|c|c|c|c|c|c|}
\hline $\mathrm{ID}^{\mathrm{a}}$ & 1 & 2 & 3 & 4 & 5 \\
\hline $\begin{array}{l}\text { Associated network } \\
\text { functions }\end{array}$ & $\begin{array}{l}\text { Cell-to-cell signaling } \\
\text { and interaction, } \\
\text { hematological } \\
\text { system development } \\
\text { and function, } \\
\text { cellular movement }\end{array}$ & $\begin{array}{l}\text { Lipid metabolism, } \\
\text { small molecule } \\
\text { biochemistry, } \\
\text { endocrine system } \\
\text { disorders }\end{array}$ & $\begin{array}{l}\text { Hepatic system } \\
\text { disease, lipid } \\
\text { metabolism, } \\
\text { molecular } \\
\text { transport }\end{array}$ & $\begin{array}{l}\text { Inflammatory } \\
\text { response, cellular } \\
\text { movement, } \\
\text { immunological } \\
\text { disease }\end{array}$ & $\begin{array}{l}\text { Hepatic system } \\
\text { disease, lipid } \\
\text { metabolism, } \\
\text { molecular } \\
\text { transport }\end{array}$ \\
\hline $\begin{array}{l}\text { Representative } \\
\text { molecules in } \\
\text { network }^{c}\end{array}$ & $\begin{array}{r}\text { Acacb, Apom, Ccnd1, } \\
\text { Cd14, Cdknla, Tlr2 }\end{array}$ & $\begin{array}{l}\text { Acoxl, Cidea/C, Lpl, } \\
\text { S100a11 }\end{array}$ & $K r t 8, P d z k 1$ & $\begin{array}{l}\text { Cd274, Lgmn, Lyz, } \\
\quad \text { Saa2 }\end{array}$ & Cyp7a1, Fdps, Socs 2 \\
\hline Score $^{\mathrm{d}}$ & 34 & 18 & 15 & 14 & 13 \\
\hline Focus molecules ${ }^{\mathrm{e}}$ & 28 & 16 & 17 & 16 & 15 \\
\hline
\end{tabular}

Network $^{\mathrm{a}}$ numbers assigned in the order of the significant score, and associated network functions ${ }^{\mathrm{b}}$ is the three most significant functions for each network

Representative molecules in network ${ }^{\mathfrak{c}}$ mean the genes showing a time-dependent steady expression pattern in each network

${ }^{\mathrm{d}}$ Score is based on a $p$ value calculation, which calculate the likelihood that the network eligible molecules that are part of a network found therein by random chance alone and the greater the number of network eligible molecules in a network, the higher the score (lower the $p$ value) will be

${ }^{\mathrm{e}}$ Focus molecules indicates the number of network eligible molecules, the genes that are eligible for network generation, per network Top Functions in the most significant functions for each network 
a

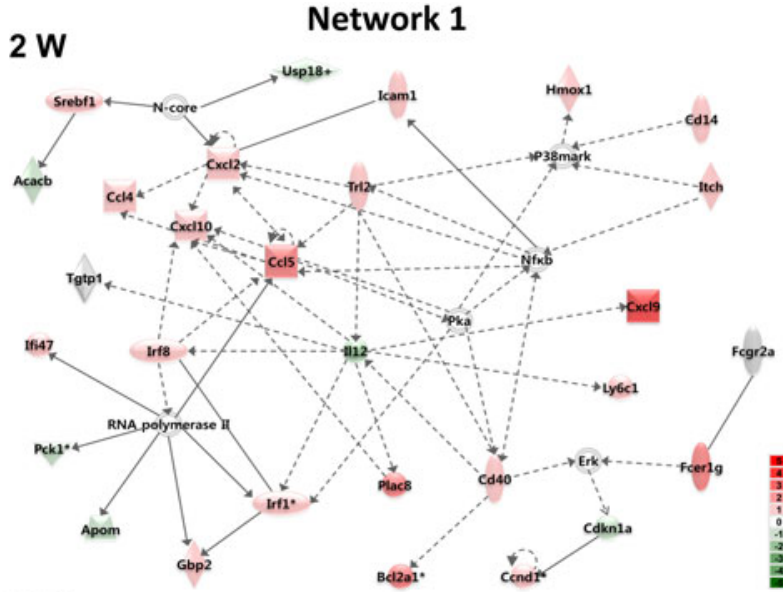

$24 \mathrm{~W}$

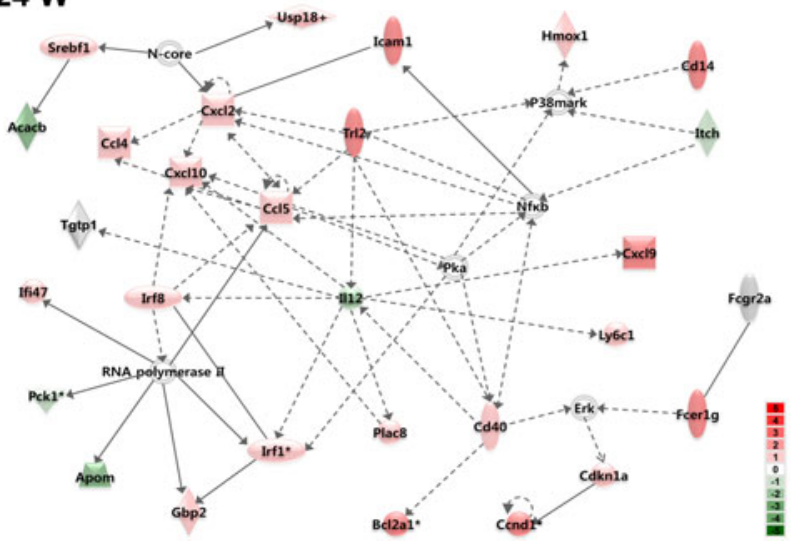

Fig. 3 Core networks and time-dependent changes in gene expression during the development of diet-induced obesity. Ingenuity pathway analysis was used to find core networks based on 332 high-fat diet responsive genes. Gene expression changes ( $\log _{2}$ fold change) are shown on as red $(+)$ or green $(-)$. Blue lines indicate genes, which were altered in a time-dependent manner from 2 weeks to 24 weeks in high-fat diet-fed mice. a Network 1; Cell-to-cell signaling and

networks are shown in Table 3. Dynamic gene expression changes in the top 5 networks are shown in video format (Supplementary material). We also show the gene expression changes in the core diet-induced obesity networks at week 2 and week 24 in Fig. 3. Some specific network genes showed marked changes in a time-dependent manner based on time course microarrays as shown in Fig. 4.

Network 1 was the most significant network composed of genes related to immune responses, cell cycle, and lipid homeostasis-related processes. Pro-inflammatory action of various chemokines accompanying toll-like receptor signaling pathway was central in Network 1 . These inflammatory genes appear to interact with $\mathrm{Cd} 14$ and critical cell cycle regulators (Ccnd1 and Cdkn1a) as well as lipid biosynthetic and transport genes (Acacb and Apom) (Fig. 3a).

Genes in Network 2 (Fig. 3b) were related to lipid metabolism, the PPAR signaling pathway, and the

\section{b $2 \mathrm{w} \quad$ Network 2}

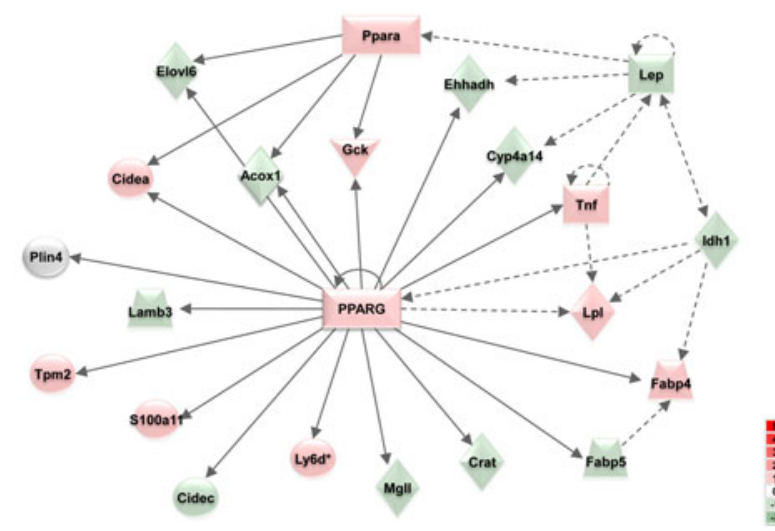

$24 \mathrm{~W}$

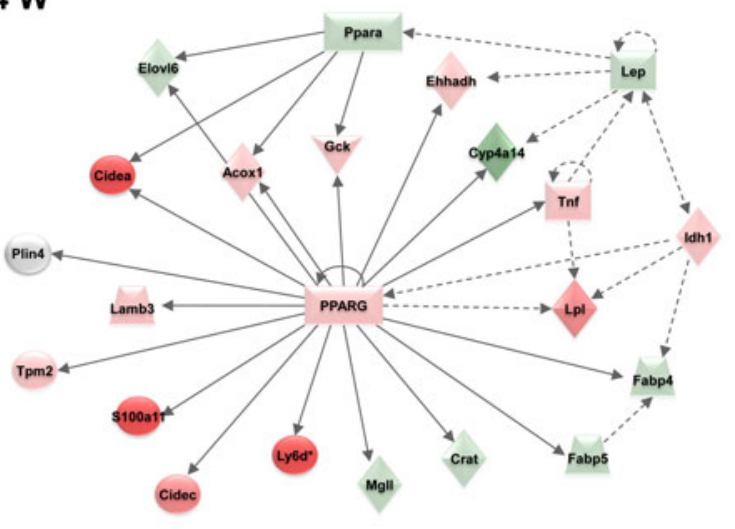

interaction, hematological system development and function, cellular movement. b Network 2; Lipid metabolism, small molecule biochemistry, endocrine system disorders. c Network 3; Hepatic system disease, lipid metabolism, molecular transport. d Network 4; Inflammatory response, cellular movement, immunological disease. e Network 5; Hepatic system disease, lipid metabolism, molecular transport (color figure online)

adipokine signaling pathway, mediated by leptin (Lep). Figure $3 \mathrm{~b}$ shows the expression of major genes in Network 2 where cell death-inducing DFFA-like effector a (Cidea), acyl-CoA oxidase 1 (Acox1), S100 calcium binding protein A11 (S100a11), lymphocyte antigen 6 complex D (Ly6d), lipoprotein lipase (Lpl), enoyl-Coenzyme A hydratase/3hydroxyacyl Coenzyme A dehydrogenase (Ehhadh), and isocitrate dehydrogenase 1 (Idh1) were significantly up-regulated in a time-dependent manner in high-fat dietfed mice compared to normal diet-fed controls.

Network 3 (Fig. 3c) was associated with hepatic system disease, lipid metabolism, and molecular transport. Network 3 was composed of hepatic-specific genes responsible for homeostasis of cholesterol and bile acids such as cytochrome P450 families and nuclear receptor subfamilies. Network 3 was also composed of genes related to "nuclear receptors in lipid metabolism and toxicity" such as Abcc2, Abcc3, Cyp7a1, Cyp8a1, Nr112, and Nr113. 


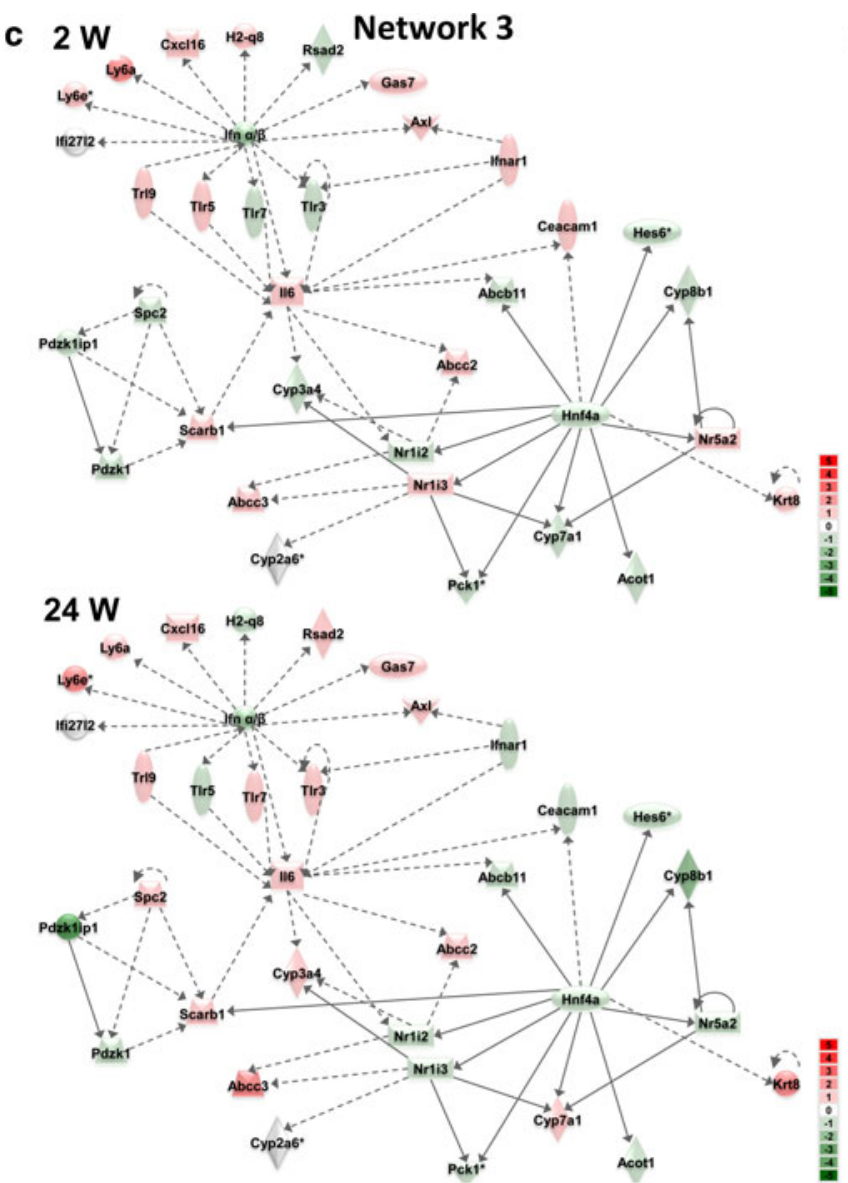

Fig. 3 continued

Among these genes, Abcb11, Abcc3, and Cyp7a1 were up-regulated, while Cyp8a1 and Nr113 were down-regulated when compared between week 2 and week 24 . Tlr 3 and Tlr7 were also slightly up-regulated genes among several toll-like receptors in Network 3.

Network 4 (Fig. 3d) was associated with the inflammatory response, cellular movement, and immunological disease and was composed of pro-inflammatory factors including tumor necrosis factor (Tnf), interferon gamma (Ifng), interleukins (Ils), and serum amyloid A2 (Saa2). In Network 4 (Fig. 3e), cytokines Il2, Il18, and Ccl2 were down-regulated, while liver fibrosis-associated genes, Csf1, Lgmm, and Gpnmb were up-regulated (Fig. 3).

Network 5, which was characterized by biological functions related to lipid and cholesterol metabolism, was composed of Ppara, Pparg, Acadm, Cyp7a1, Me1, Fdps, Fads1, Fads2, and Ptgs2. Network 5 included down-regulated genes related to the biosynthesis of cholesterol and fatty acids (Fdps and Me1) as well as genes playing a critical role in insulin and adipokine signaling pathways (Ppargc1a and Socs2). Furthermore, expression of Cyp7A1 responsible for bile acid synthesis, as well as Ptgs2,

\section{d $2 \mathrm{~W} \quad$ Network 4}

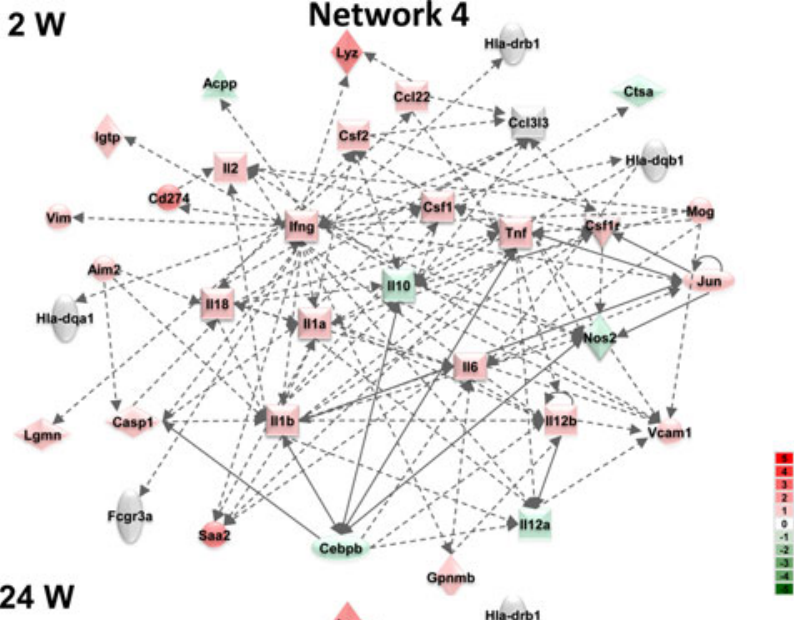

$24 \mathrm{~W}$

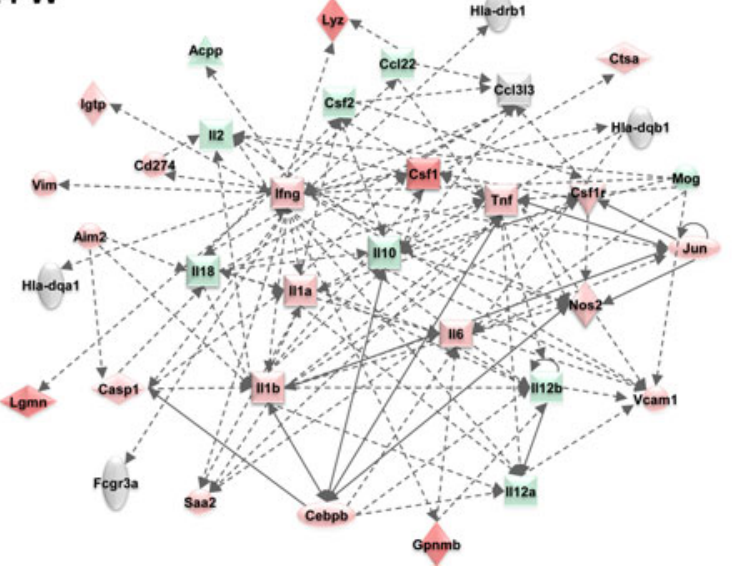

Acadm, and Gabpa responsible for inflammatory prostaglandin were down-regulated.

Hepatic steatosis hub genes connected via a protein-protein interaction (PPI) network

Next, we sought to identify hub genes that may drive the development of obesity-related comorbidities focusing specifically on hepatic steatosis, an early event in the development of NASH. When we overlaid "diseases and functions" on the merged core networks in IPA, forty-one genes were associated with the "inflammatory response" $(p$ value $9.98 \mathrm{E}-30)$ and fourteen genes were associated with "hepatic steatosis" ( $p$ value $2.90 \mathrm{E}-12$ ). We found nine genes associated with both the "inflammatory response" and "hepatic steatosis," these were Ccnd1, Tnf, Tlr2, Il10, Lep, Cd14, Fabp4, Pparg, and Ppara. Ccnd1, Tlr2, and Cd14 were selected as potential hepatic steatosis hub genes as these genes showed distinct time-dependent expression in the high-fat diet-fed mice. To explore further potential molecular interactions between these hub genes, we first built three separate PPI networks (one depth 


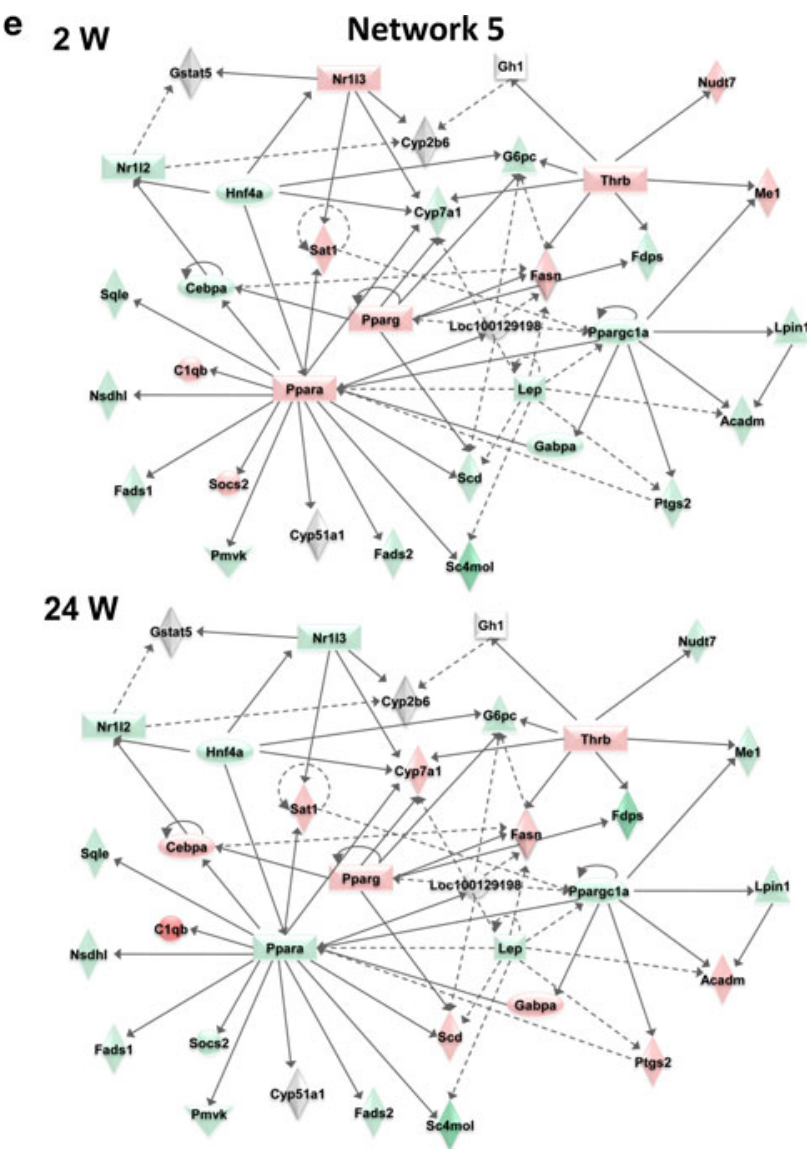

Fig. 3 continued

degree) using the Mus musculus protein-protein interaction (PPI) database (Jensen et al. 2009) to generate further seed genes (Fig. 5a). Of the seed genes identified using this approach, eighteen seed genes were differentially expressed in the high-fat diet-fed mice, including Cond1, Cd14, Cd44, Csf1r, Cyp8b1, Egfr, H2-Aa, Junb, Lgals3, Lpl, Nsdhl, S100a8, and Tlr2 (Fig. 5a), of which thirteen genes were mapped to proteins via MiMI in Cytoscape. We then built an expanded hepatic steatosis PPI network based on these thirteen genes using the Cytoscape plug-in MiMI (Fig. 5b), with genes without a linkage to the central PPI network removed. Accordingly, as shown in Fig. 5c, Tlr2, Cd14, and Ccnd1 were connected via a PPI network associated with the "ErbB and insulin signal pathway (yellow dotted line)." In addition, these hub genes interacted with proteins forming a cluster associated with "lipid transport system" and "DNA damage responses or repair system (green dotted line)."

To check whether a similar PPI network exists in humans, we mapped the nine mouse genes associated with both the "inflammatory response" and "hepatic steatosis" to their human orthologs and built a human hepatic steatosis PPI network (Fig. 5). Similarly, Tlr2, Cd14, and
Ccnd1 were associated through Egfr-mediated signaling molecules, such as Src, Pi3 k, ser/thr protein kinase, and Stat3 in the human hepatic steatosis PPI network (Fig. 5).

Figure 6 shows the dynamic changes related to hepatic steatosis PPI network based on time course microarrays of HFD-fed mice compared to ND-fed mice. During progression of diet-induced obesity, 6 genes (Ccnd, Cd14, Csf1r, Lgals3, Lpl, and Tlr2) among 7 were up-regulated in the hepatic steatosis PPI network.

\section{Discussion}

We reveal dynamic changes in the core molecular networks underlying the development of diet-induced obesity. Importantly, we used a progressive diet-induced obesity model involving C57BL/6 J mice fed a physiological relevant high-fat diet ( $20 \% \mathrm{kcal}$ fat) over 24 weeks compared to age-matched normal diet-fed controls. Morphological analysis revealed hepatic fibrosis was evident after 16 weeks, while we previously reported hepatic lipid accumulation was evident after 2 weeks in this dietinduced obesity model (Do et al. 2011). Hepatic lipid accumulation is an early event in the development of nonalcoholic hepatic steatosis (NASH), which can later lead to hepatic fibrosis and eventually liver cirrhosis (Cohen et al. 2011). Inflammation is strongly associated with NASH development in animals and humans. In the present study, we identified Tlr2, Cd14, and Ccndl as hub genes associated with both hepatic steatosis and inflammation, and built a protein-protein interaction network to determine further interrelated proteins and biological functions.

Core molecular networks underlying the development of diet-induced obesity

To elucidate the core molecular networks in liver underlying the development of diet-induced obesity, high-fat diet responsive genes were analyzed using the Ingenuity knowledge base, which consists of expert curated molecular interactions. The high-fat diet responsive genes formed five core networks. Network 1 consisted of genes associated with movement, trafficking, and differentiation of immune cells, as well as fatty acid oxidation, lipid transport, and cell cycle. Tlr2, Ccl5, Cxcl9, Itch, and Cd14 were transcriptionally up-regulated, while Acacb and Apom were down-regulated consistently in Network 1 from week 2 to week 24 in HFD-fed mice. Acacb and Apom play a role in fatty acid oxidation and lipid transport. Acacb catalyzes the carboxylation of acetyl-CoA to malonyl-CoA, the ratelimiting step in fatty acid synthesis. Acacb is also reported to regulate fatty acid oxidation via malonyl-CoA inhibition of carnitine palmitoyltransferase I, the rate-limiting step in 
Table 3 Top bio functions associated with high-fat diet responsive genes identified in long-term high-fat diet-fed C57BL/6 J mice

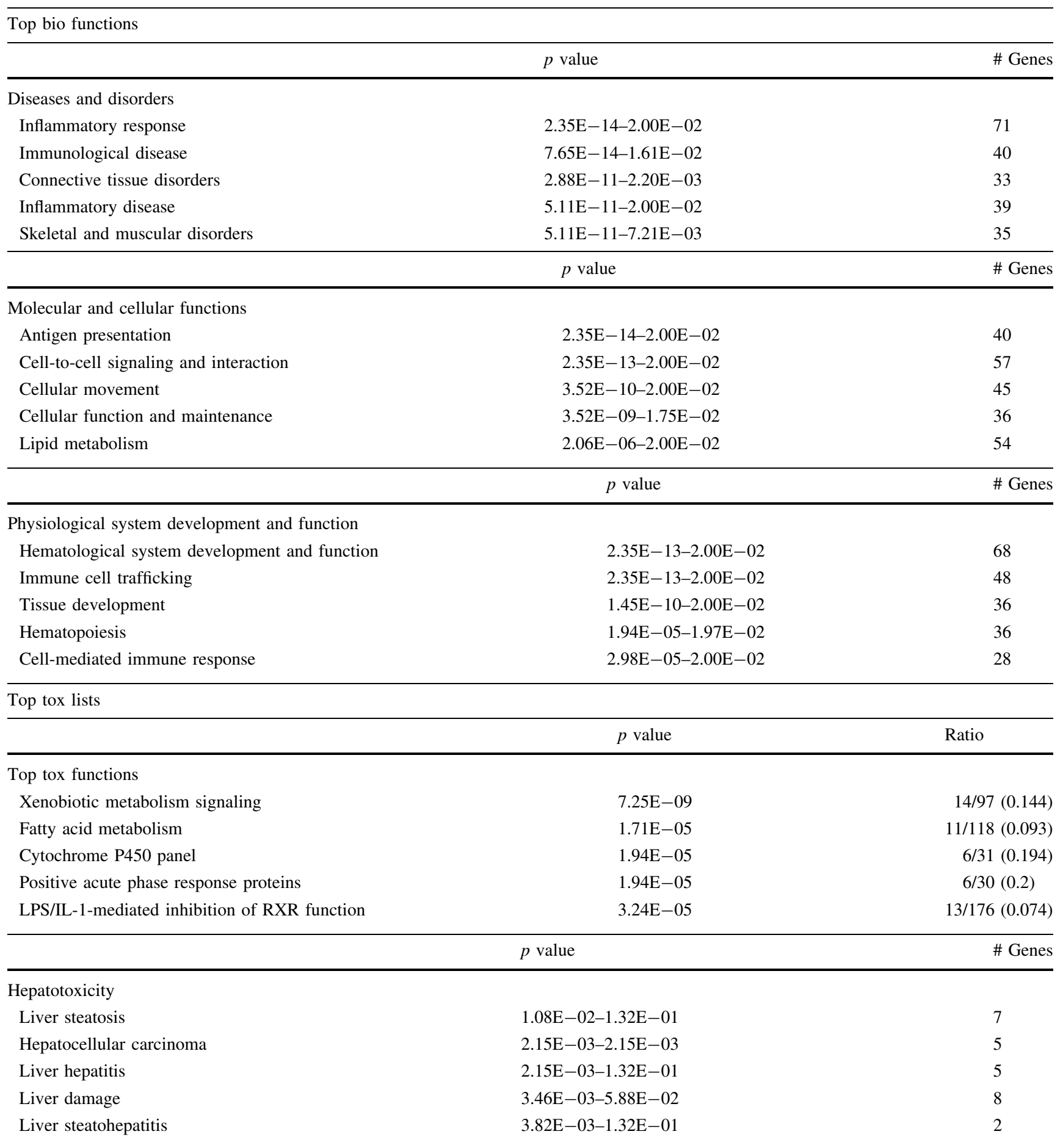

fatty acid uptake, and oxidation by mitochondria (AbuElheiga et al. 2001). Genes involved in the innate immune system and the trafficking of immune cells, including Tlr2, Cd14, Icam1, and various chemokines were consistently up-regulated in Network 1. Toll-like receptors $(T l r)$ are associated with liver diseases including alcoholic liver injury, ischemia/reperfusion liver injury, liver fibrosis, and liver cancer (Seki et al. 2007; Imaeda et al. 2009). Tlr2 recognizes conserved pathogen-associated molecular patterns and plays a critical role in the activation of the innate immune system in response to invading microorganisms (Akira 2003). In addition, blockade of Tlr2 signaling is reported to prevent insulin resistance in HFD-fed mice (Caricilli et al. 2008; Himes and Smith 2010). The role of 

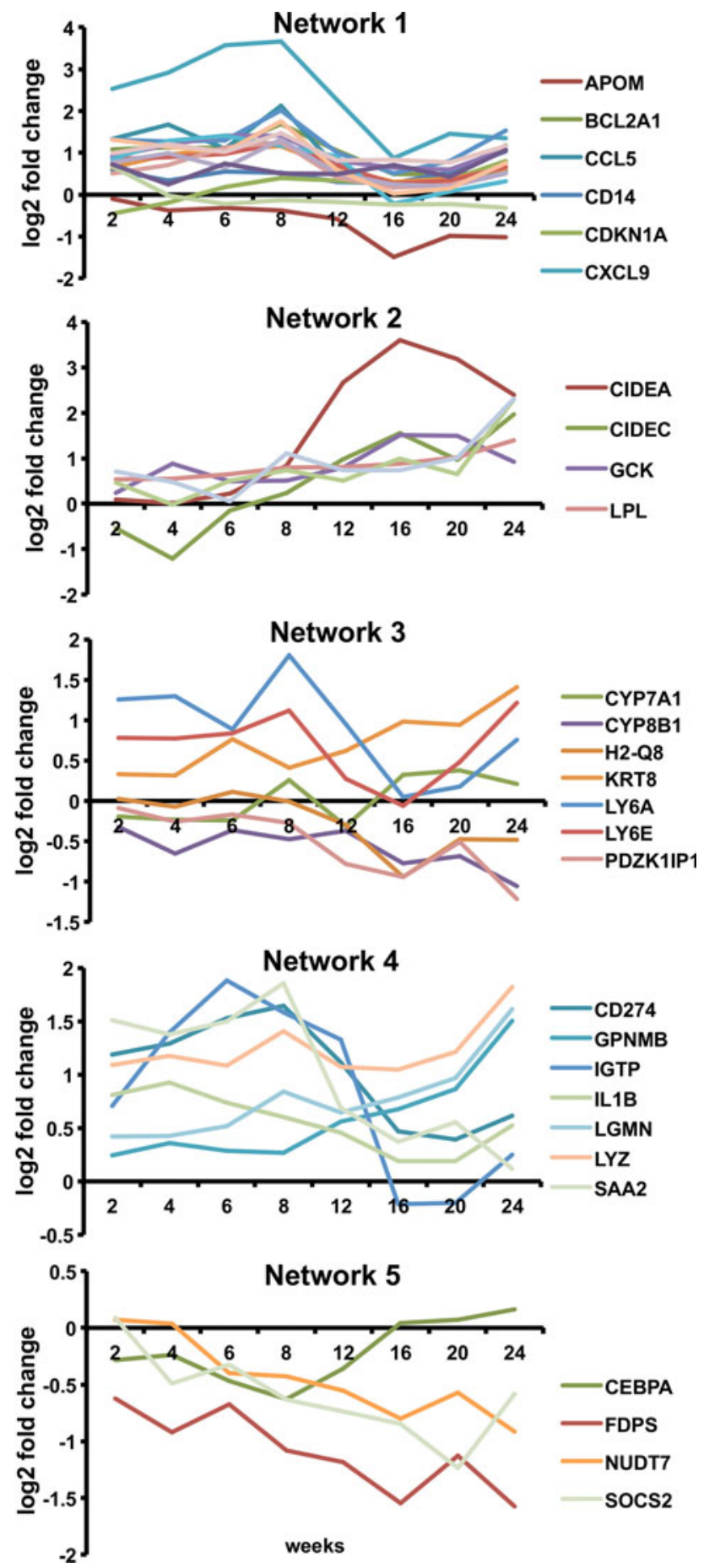

Fig. 4 Time-dependent gene expression changes in network 1-5 over 24 weeks in high-fat diet-fed mice compared to normal diet-fed mice. Based on probe intensity from Illumina Mouse WG-6 v2 beadchips

Tlr4 and Tlr9 in NASH has not been well studied; nevertheless, Cd14 mediates the signaling of Tlr2 and Tlr4; therefore, $C d 14$-mediated $T l r$ activation may contribute to the metabolic complications associated with obesity via increased inflammation (Roncon-Albuquerque et al. 2008).
Two critical cell cycle regulators, CyclinD1 $(C c n d l)$ and cyclin-dependent kinase inhibitor 1A (Cdknla) in Network 1 , are also associated with innate immune system activation and were increased in a time-dependent manner in high-fat diet-fed mice.

Genes in Network 2 were related to lipolysis, lipid uptake and lipid transport, and interestingly involved in liver fibrosis, steatotic liver, and NAFLD (Shechter et al. 2003; Lydatakis et al. 2006; Guillén et al. 2009; Jinno et al. 2010; Yang et al. 2010). Tnf, Cidea, Acoxl, S100a11, Ly6d, Lpl, and Idhl were up-regulated in a time-dependent manner compared to normal diet - control. The genes in Network 2 appear to be regulated by peroxisome proliferator-activated receptor-gamma (Pparg), a critical metabolic regulator implicated in pathology of numerous diseases including obesity, diabetes, atherosclerosis, and cancer (Chawla et al. 2001; Libby 2001; Boitier et al. 2003). Pparg activates the formation of lipid droplets from triglycerides in hepatic tissues. The surface of the lipid droplet is coated with proteins of the perilipin family including Cide$a$, Cide-b, and Cide- $c$, which can regulate lipid metabolism and mediate excess accumulation of intracellular lipids associated with obesity via hydrolysis of hepatic lipid droplets (Zhou et al. 2003; Li et al. 2007). Cidea-null mice are lean and resistant to diet-induced obesity and diabetes, partly due to a significantly higher metabolic rate compared with wild-type mice (Zhou et al. 2003).

$I d h l$ gene expression is regulated by sterols and activated by SREBP-1a and SREBP-2 in human hepatoma HepG2 cells and appears to regulate lipogenesis in hepatic cells (Shechter et al. 2003). Idhl activity can be coordinately regulated with the cholesterol and fatty acid biosynthetic pathways. Idhl gene expression was up-regulated from week 16, which may have accelerated hepatic lipogenesis, together with $\mathrm{Lpl}$ in our diet-induced obesity model. Fabp4 plays a role in fatty acid binding, uptake, transport, and was down-regulated in high-fat diet-fed mice after 20 weeks.

Ly6d, which marks the earliest stage of B cell specification and identifies the branch point between $B$ cell and $T$ cell development, was found to increase in a time-dependent manner during diet-induced obesity. Interestingly, Acoxl (acyl-CoA oxidase 1) and Lamb3 gene expressions were only up-regulated at week 24 . Acoxl, a rate-limiting enzyme in peroxisomal fatty acid beta-oxidation, was consistently down-regulated up to week 20 but was up-regulated at week 24. Interestingly, mice nullizygous for both Ppara and Acox 1 lack spontaneous hepatic peroxisome proliferation and show a marked decrease in hepatic steatosis (Hashimoto et al. 1999). The time course of $L a m b 3$ expression was very similar to that of Acox 1, Lamb3 was consistently down-regulated up to week 20 but appeared to be increased at week 24 . Lamb3 appeared to be one of the early genes closely involved in the development of liver fibrosis. Lamb3 expression in NASH patients with fibrosis is reported to be significantly 
a PPI network built with TIr2, Cd14, Ccnd1 using String database
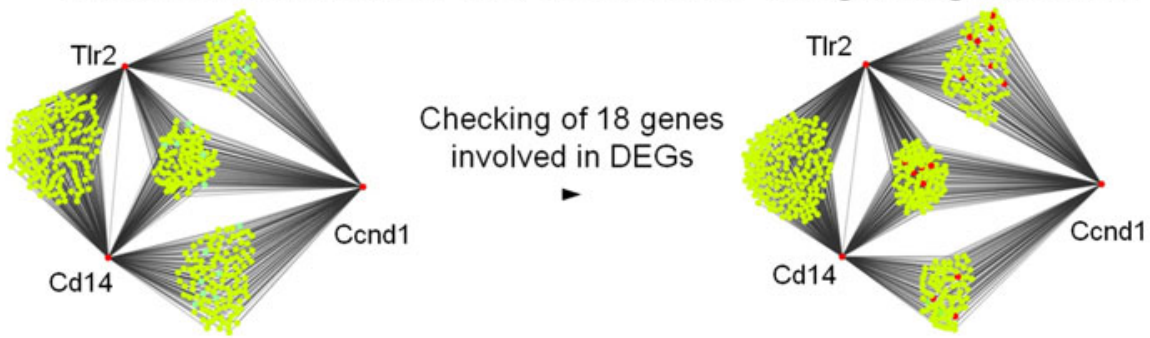

b PPI network built with 18 genes containing TIr2, Cd14 and Cond1

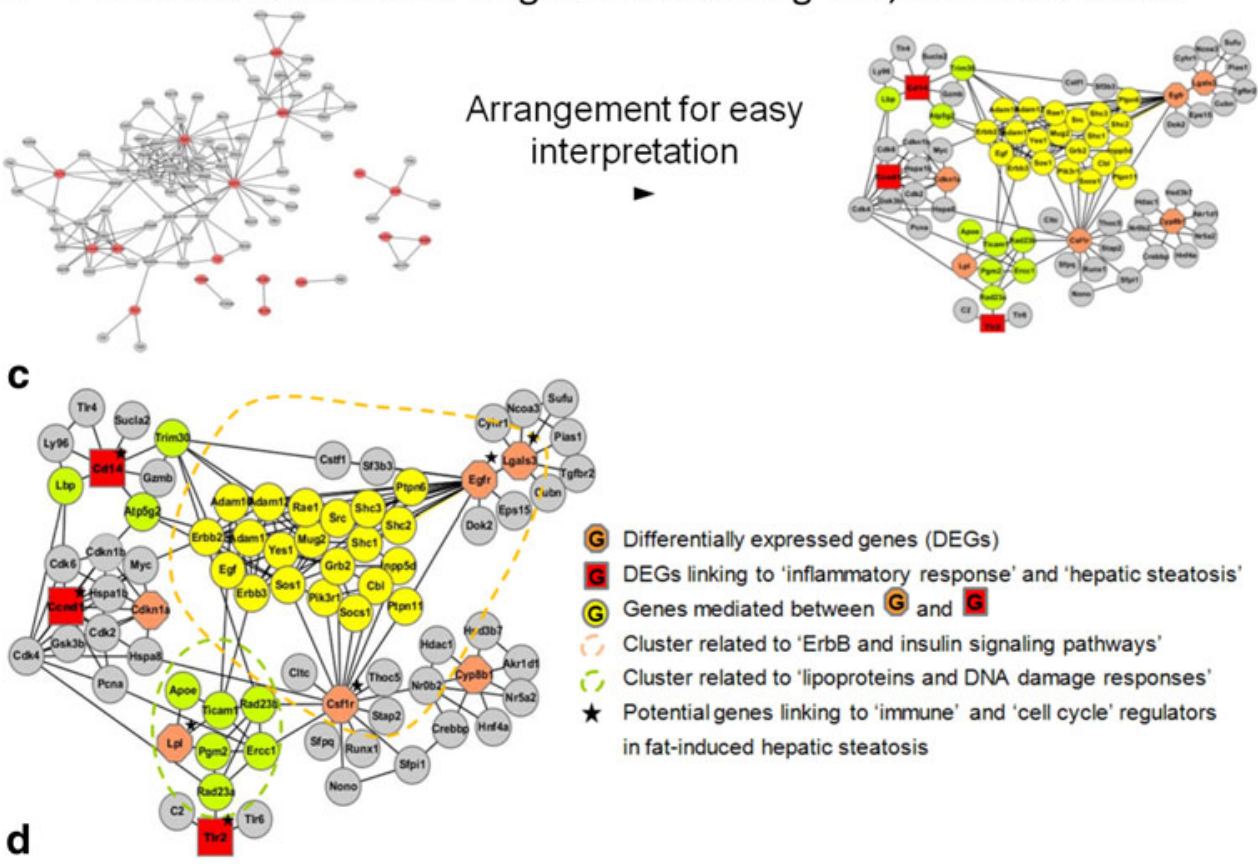

PPI network linking the 'inflammation response' and 'hepatic steatosis'
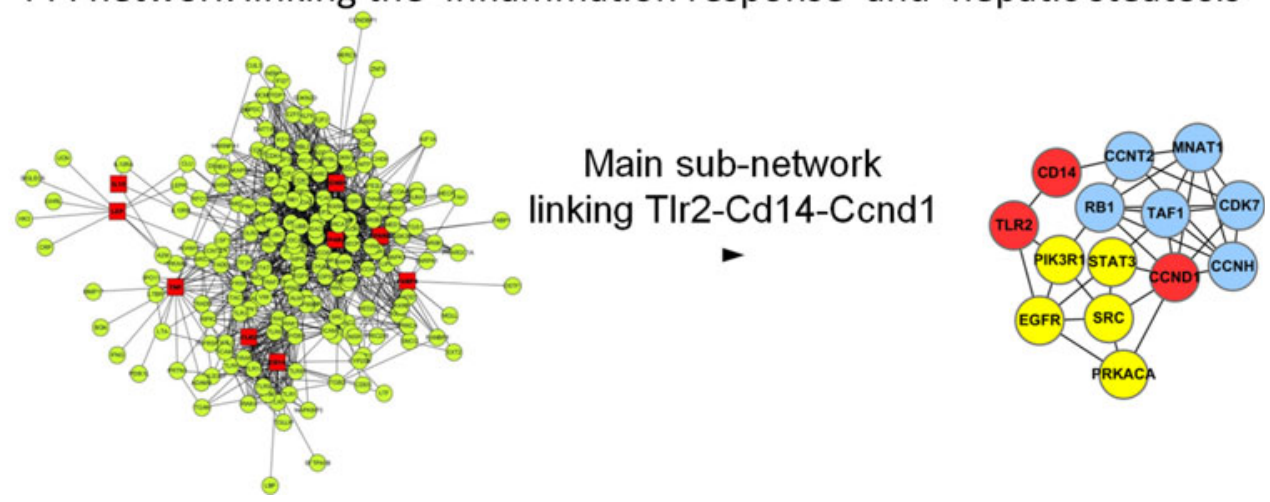

higher than in NASH patients without fibrosis (Lydatakis et al. 2006). In the current study, morphological analysis of liver tissue indicated central venule fibrosis developed in HFD-fed mice after 16 weeks compared to ND-fed mice. S100all expression showed a time-dependent increase over 24 weeks, which was more prominent later during the development of diet-induced obesity. S100A11 is reportedly involved in tumor promoter activity as elevated protein level of S100A11 was found in hepatocellular carcinoma (HCC) cell lines with high metastatic potential. Thus, it is plausible that S100A11 may be an early biomarker of progression from liver steatosis to metastasis. $\mathrm{Lpl}$ gene expression was also consistently high over 24 weeks. $\mathrm{Lpl}$ plays roles in the clearance of plasma triglycerides from VLDL and hence may cause accumulation of hepatic triglycerides and FFA, which can be toxic to hepatocytes.

Genes in Network 3 were mainly hepatic-specific genes responsible for the homeostasis of cholesterols and bile 
4 Fig. 5 Hepatic steatosis protein-protein interaction (PPI) network for (I) mice and (II) humans. IPA revealed Tlr2, Cd14, and Ccnd1 were high-fat diet responsive hub genes associated with both the inflammatory response and hepatic steatosis. Using the PPI database (I), eighteen high-fat responsive genes were selected from PPI network built with $T l r 2, C d 14$, and $C c n d 1$ using String database (a). Final PPI network was constructed with 13 matched genes among 18 genes in Cytoscape plug-in for MiMI and rearranged for easy interpretation (b). Significantly differentially expressed genes linking the inflammatory response and hepatic steatosis were $T l r, C d 14$, and $C c n d 1$ (red nodes). The protein-protein interaction network revealed two gene clusters associated with "lipid transport and DNA damage repair systems" (green nodes) and "ErbB/insulin signaling pathways" (yellow nodes). Lpl, Egfr, Lgals3, and Csflr may play a role in the progression of hepatic insulin resistance, macrophage activation to severe non-alcoholic fatty liver disease in diet-induced obesity (c). (II) A human PPI network was built with 9 genes linking between "inflammation response" and "hepatic steatosis" using Cytoscape plug-in for MiMI. Tlr2 and Cd14 were associated with $C c n d 1$ by Egfr/insulin signaling molecules such as Egfr, Pik3r1, Prkaca, Src, and Stat3 (color figure online)

acids such as cytochrome P450 families and nuclear receptor subfamilies (Fig. 3). Cyp7A1 gene expression was consistently up-regulated, and Cyp7Al encodes cholesterol- $7 \alpha$-hydroxylase, a rate-limiting enzyme in the bile acid biosynthesis pathway that converts cholesterol into bile acids. Nr5a2 (Lrh-1, liver receptor homolog-1) is a bile acid transporter, which mediates bile acid homeostasis and steroidogenesis together with the Cyp7A1. Since Lrh-1 plays a key role in hepatic sterol metabolism as a bile acid transporter, several of its target genes are crucial to the regulation of reverse cholesterol transport, bile acid synthesis, and enterohepatic circulation (Fayard et al. 2004). Lrh-1 down-regulation is probably due to the decreased cholesterol biosynthesis and reverse cholesterol transport caused by high-fat feeding. Cholesterol feeding in rodents is reported to decrease sterol $12 \alpha$-hydroxylase (Cyp $8 B 1$ ) and increase Cyp7A1, mediated by SREBP regulation (Le Martelot et al. 2009), indicating these are regulatory enzymes of bile acid synthesis. The dynamic transcriptional changes in Network 3 genes indicate hepatic sterol biosynthesis was decreased and bile acid biosynthesis was increased progressively in the HFD-fed mice, most likely attributable to excess cholesterol influx into liver from excess dietary intake.

Genes forming Network 4 were associated with the inflammatory response, cellular movement, and immunological disease. Network 4 was composed of pro-inflammatory factors such as Tnf, Ifng, IllA, and Saa2. Network 4 also contained a few specific genes that were altered in a time-dependent manner. Gpnmb, Lgnm, Lyz, and Saa2 gene expression was up-regulated. Although Gpnmb is a novel osteoclastic protein that plays a key role in osteoclast differentiation and activity (Sheng et al. 2008), Gpnmb is also found in inflammatory liver macrophages (Haralanova-Ilieva et al. 2005). Lgnm encodes the legumain protein, which

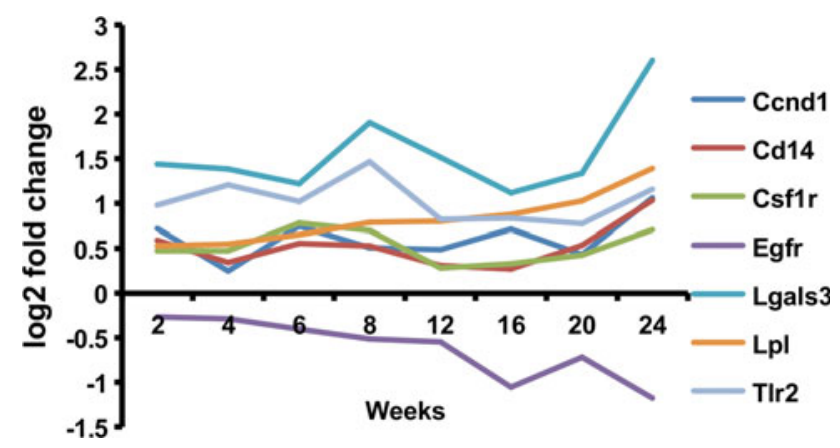

Fig. 6 Time-dependent changes in central molecules of the hepatic steatosis PPI network which are involved in protein-protein interactions linking steatosis and inflammation in mice fed high-fat diet over 24 weeks

is involved in the processing of bacterial peptides and endogenous proteins via major histocompatibility complex (MHC) class II proteins in the lysosomal/endosomal degradation pathway. Accordingly, dynamic changes in genes in Network 4 may underlie the development of chronic inflammation, which occurs as a consequence of a longterm high-fat diet.

Genes in Network 5 were collectively associated with hepatic system disease, lipid metabolism, and molecular transport. Network 5 was composed of genes related to various metabolic processes of macromolecules such as gluconeogenesis (Ppargcla), oxidation (Ppara), as well as biosynthesis (Me1) of fatty acids, cholesterols ( $F d p s)$, bile acids (Cyp7A1), and prostaglandin (Ptgs2). Expression of Fdps was decreased in a time-dependent manner along with its neighbors (Ppara, Ppargcla, Scd, and Socs2; Fig. 3). The transcriptional profile of Ppara, Ppargcla, Socs2, and Me1 were all decreased in time-dependent manner, which may be attributable to negative feedback due to elevated plasma and hepatic cholesterol, as well as hepatic triglycerides due to the high-fat feeding. The Ppara and Ppargcla transcriptions were related to $F a d s$, which regulates unsaturation of fatty acids, Ppara was also associated with Fads 1 via Socs 2 . In rat islets, Socs 2 is reported to suppress glucose-stimulated insulin secretion and Socs 2 is related to increased susceptibility to T2D in humans (Kato et al. 2006). We found $N s d h$, a non-specific aldehyde dehydrogenase, was down-regulated via Ppara in Network 5. Endogenous aldehydes are formed during the metabolism of alcohols, amino acids, biogenic amines, vitamins, steroids, and lipids. Network 5 also included Acadm (acyl-CoA dehydrogenase for medium fatty acids), an enzyme essential for converting specific fatty acids to energy during fasting particularly in the liver, Ptgs 2 (prostaglandin-endoperoxide synthase 2) which plays a role in inflammation as indicated by severe nephropathy developed in Ptrs2-null mice (Norwood et al. 2000) and Gab$p a$ (GA-binding protein alpha chain) which is involved in the activation of cytochrome oxidase expression and nuclear 
control of mitochondrial function (Virbasius et al. 1993; Virbasius and Scarpulla 1994).

Hepatic steatosis hub genes interact

via a protein-protein interaction network

Diet-induced obese animals are characterized by early evidence of multiple obesity comorbidities, dependent on genetic background, diet composition, and duration. Hepatic steatosis and hepatic fibrosis are involved in the pathogenesis of NASH and were evident in our model of diet-induced obesity, despite modest high-fat diet intake. By merging the core diet-induced obesity networks, we identified Tlr2, Cd14, and Ccndl as hub genes related to both liver steatosis and the inflammatory response according to the IPA Knowledge base. We found these liver steatosis hub genes were interconnected at the molecular level via a protein-protein interaction network. Functional analysis of the protein-protein interaction network revealed $T l r 2, C d 14$, and $C c n d l$ interact with protein clusters associated with the ErbB and insulin signaling pathway, lipid transport, and DNA damage response.

ErbB is a downstream effector of stress-induced insulin resistance, and stress-dependent transcription of ErbB2/ ErbB3 receptors triggers a PI3 $\mathrm{K}$ cascade that induces serine phosphorylation of IRS proteins culminating in insulin resistance (Hemi et al. 2002). Insulin resistance is a pathological state in which target cells fail to respond to changes in circulating insulin and is associated with obesity, type 2 diabetes, as well as conditions of acute and chronic stress caused by high-fat feeding. The PPI network revealed the hepatic steatosis hub genes were interconnected via Egfr, Lgals3, and Csf1r, which form a protein cluster involved in ErbB and insulin signaling, as well as $L p l$ which belongs to a protein cluster associated with lipid transport. $\mathrm{Lpl}$ gene expression was consistently up-regulated in a time-dependent manner over 24 weeks, while Csflr and Lgals gene expressions were up-regulated later after 16 week in high-fat diet-fed mice, conversely Egfr gene expression was down-regulated. Epidermal growth factor receptor $(E g f r)$ is one of the proinflammatory factors which is reported to play a role in the activation of the carcinogenesis-associated signal transducer and transcription-3 (Stat3) (Starska et al. 2009). Cyclin D1 plays a critical role in transition from the G1 to $\mathrm{S}$ Phase of the cell cycle. Amplification, overexpression, and variations of the cyclin D1 gene have been detected in several types of cancers, including liver cancers (Zhang et al. 1993). Lgals3 is associated with cirrhosis in hepatocytes and has been reported not only to activate the expression of cyclin D1 but also to regulate cell proliferation (Matsuda et al. 2008). Lgals3 and Csflr appeared to contribute to ErbB/ insulin signaling pathways via maintaining the negative association with Egfr (Merlin et al. 2011), as well as recruiting insulin signaling molecules (Hamilton 1997).

We acknowledge the hepatic steatosis PPI network we present here remains to be verified in diet-induced obesity in vivo. Nevertheless, our findings highlight, hub genes related to steatosis, a common obesity comorbidity, appear to be highly connected via underlying protein-protein interaction networks. Therefore, perturbation of these hub genes may have far wider functional effects on insulin signaling, lipid transport, and DNA damage. Conversely, small molecule inhibitors of nodes in PPI networks may lead to dynamic changes in hub gene expression. A major strength of the current study was the use of a long-term diet-induced obesity model which recapitulated morphological changes in liver observed in human NASH, such as hepatic lipid accumulation, inflammation, and fibrosis. We used a physiologically relevant high-fat $(20 \% \mathrm{kcal})$ diet to induce obesity and NASH over 24 weeks, rather than using excessively high-fat ( $80 \% \mathrm{kcal}$ ) diets suggested by recent murine NASH models (Hebbard and George 2011; Ogasawara et al. 2011). In future studies, it may be worthwhile to identify hub genes and protein-protein interaction networks related to the development of other obesity comorbidities including insulin resistance and type 2 diabetes.

\section{Conclusion}

High-fat diet responsive genes form several core networks underlying the development of diet-induced obesity. We identified Tlr2, Cd14, and Ccndl as major hub genes associated with both hepatic steatosis and inflammation. $T l r 2, C d 14$, and Ccndl are interconnected via a proteinprotein interaction network, which form clusters associated with the ErbB/insulin signaling pathway, lipid transport, and DNA damage. Therefore, Tlr2, Cd14, and Ccndl represent possible targets to prevent the development of NASH in diet-induced obesity. However, further study is needed to elucidate the exact roles of these proteins in the development of NASH and progression to liver cirrhosis.

Acknowledgments This work was supported by the National Research Foundation of Korea (NRF) grant funded by the Korea government (MEST) (No. 2011-0000912, 2012M3A9C4048818) and grants from an Omics-Based Integration Database for Cancer Interpretation (KGM1161012, KGM0661113) funded by the Korea Research Institute of Bioscience and Biotechnology (KRIBB).

\section{References}

Abu-Elheiga L, Matzuk MM, Abo-Hashema KA, Wakil SJ (2001) Continuous fatty acid oxidation and reduced fat storage in mice lacking acetyl-CoA carboxylase 2. Science 291:2613-2616 
Akira S (2003) Mammalian toll-like receptors. Curr Opin Immunol 15:5-11

Baranova A, Schlauch K, Elariny H, Jarrar M, Bennett C, Nugent C, Gowder SJ, Younoszai Z, Collantes R, Chandhoke V, Younossi ZM (2007) Gene expression patterns in hepatic tissue and visceral adipose tissue of patients with non-alcoholic fatty liver disease. Obes Surg 17:1111-1118

Bertola A, Bonnafous S, Anty R, Patouraux S, Saint-Paul M-C, Iannelli A, Gugenheim J, Barr J, Mato JM, Le Marchand-Brustel Y, Tran A, Gual P (2010) Hepatic expression patterns of inflammatory and immune response genes associated with obesity and NASH in morbidly obese patients. PLoS ONE 5:e13577

Boitier E, Gautier J-C, Roberts R (2003) Advances in understanding the regulation of apoptosis and mitosis by peroxisome-proliferator activated receptors in pre-clinical models: relevance for human health and disease. Comp Hepatol 2:3

Calvano SE, Xiao W, Richards DR, Felciano RM, Baker HV, Cho RJ, Chen RO, Brownstein BH, Cobb JP, Tschoeke SK, MillerGraziano C, Moldawer LL, Mindrinos MN, Davis RW, Tompkins RG, Lowry SF (2005) A network-based analysis of systemic inflammation in humans. Nature 437:1032-1037

Caricilli AM, Nascimento PH, Pauli JR, Tsukumo DML, Velloso LA, Carvalheira JB, Saad MJA (2008) Inhibition of toll-like receptor 2 expression improves insulin sensitivity and signaling in muscle and white adipose tissue of mice fed a high-fat diet. J Endocrinol 199:399-406

Chawla A, Barak Y, Nagy L, Liao D, Tontonoz P, Evans RM (2001) PPAR-gamma dependent and independent effects on macrophage-gene expression in lipid metabolism and inflammation. Nat Med 7:48-52

Cohen JC, Horton JD, Hobbs HH (2011) Human fatty liver disease: old questions and new insights. Science 332:1519-1523

Do G-M, Oh HY, Kwon E-Y, Cho Y-Y, Shin S-K, Park H-J, Jeon S-M, Kim E, Hur C-G, Park T-S, Sung M-K, McGregor RA, Choi M-S (2011) Long-term adaptation of global transcription and metabolism in the liver of high-fat diet-fed C57BL/6 J mice. Mol Nutr Food Res 55:173-185

Fayard E, Auwerx J, Schoonjans K (2004) LRH-1: an orphan nuclear receptor involved in development, metabolism and steroidogenesis. Trends Cell Biol 14:250-260

Finucane MM, Stevens GA, Cowan MJ, Danaei G, Lin JK, Paciorek CJ, Singh GM, Gutierrez HR, Lu Y, Bahalim AN, Farzadfar F, Riley LM, Ezzati M (2011) National, regional, and global trends in body-mass index since 1980: systematic analysis of health examination surveys and epidemiological studies with 960 country-years and 9.1 million participants. Lancet 377:557-567

Fraulob JC, Ogg-Diamantino R, Fernandes-Santos C, Aguila MB, Mandarim-de-Lacerda CA (2010) A mouse model of metabolic syndrome: insulin resistance, fatty liver and non-alcoholic fatty pancreas disease (NAFPD) in C57BL/6 mice fed a high fat diet. $\mathrm{J}$ Clin Biochem Nutr 46:212-223

Gao J, Ade AS, Tarcea VG, Weymouth TE, Mirel BR, Jagadish HV, States DJ (2009) Integrating and annotating the interactome using the MiMI plugin for cytoscape. Bioinformatics 25:137138

Gawrieh S, Baye TM, Carless M, Wallace J, Komorowski R, Kleiner DE, Andris D, Makladi B, Cole R, Charlton M, Curran J, Dyer TD, Charlesworth J, Wilke R, Blangero J, Kissebah AH, Olivier M (2010) Hepatic gene networks in morbidly obese patients with nonalcoholic fatty liver disease. Obes Surg 20:1698-1709

Gregoire FM, Zhang Q, Smith SJ, Tong C, Ross D, Lopez H, West DB (2002) Diet-induced obesity and hepatic gene expression alterations in C57BL/6 J and ICAM-1-deficient mice. Am J Physiol Endocrinol Metab 282:E703-E713
Guh DP, Zhang W, Bansback N, Amarsi Z, Birmingham CL, Anis AH (2009) The incidence of co-morbidities related to obesity and overweight: a systematic review and meta-analysis. BMC Public Health 9:88

Guillén N, Navarro MA, Arnal C, Noone E, Arbonés-Mainar JM, Acín S, Surra JC, Muniesa P, Roche HM, Osada J (2009) Microarray analysis of hepatic gene expression identifies new genes involved in steatotic liver. Physiol Genomics 37:187-198

Hamilton JA (1997) CSF-1 signal transduction. J Leukoc Biol 62:145-155

Haralanova-Ilieva B, Ramadori G, Armbrust T (2005) Expression of osteoactivin in rat and human liver and isolated rat liver cells. J Hepatol 42:565-572

Hashimoto T, Fujita T, Usuda N, Cook W, Qi C, Peters JM, Gonzalez FJ, Yeldandi AV, Rao MS, Reddy JK (1999) Peroxisomal and mitochondrial fatty acid beta-oxidation in mice nullizygous for both peroxisome proliferator-activated receptor alpha and peroxisomal fatty acyl-CoA oxidase. Genotype correlation with fatty liver phenotype. J Biol Chem 274:19228-19236

Hebbard L, George J (2011) Animal models of nonalcoholic fatty liver disease. Nat Rev Gastroenterol Hepatol 8:35-44

Hemi R, Paz K, Wertheim N, Karasik A, Zick Y, Kanety H (2002) Transactivation of ErbB2 and ErbB3 by tumor necrosis factoralpha and anisomycin leads to impaired insulin signaling through serine/threonine phosphorylation of IRS proteins. J Biol Chem 277:8961-8969

Himes RW, Smith CW (2010) Tlr2 is critical for diet-induced metabolic syndrome in a murine model. FASEB J 24:731-739

Ideker T, Sharan R (2008) Protein networks in disease. Genome Res 18:644-652

Imaeda AB, Watanabe A, Sohail MA, Mahmood S, Mohamadnejad M, Sutterwala FS, Flavell RA, Mehal WZ (2009) Acetaminophen-induced hepatotoxicity in mice is dependent on Tlr9 and the Nalp3 inflammasome. J Clin Invest 119:305-314

Jensen LJ, Kuhn M, Stark M, Chaffron S, Creevey C, Muller J, Doerks T, Julien P, Roth A, Simonovic M, Bork P, von Mering C (2009) STRING 8-a global view on proteins and their functional interactions in 630 organisms. Nucleic Acids Res 37:D412-D416

Jinno Y, Nakakuki M, Sato A, Kawano H, Notsu T, Mizuguchi K, Shimano H (2010) Cide-a and Cide-c are induced in the progression of hepatic steatosis and inhibited by eicosapentaenoic acid. Prostaglandins Leukot Essent Fatty Acids 83:75-81

Kato H, Nomura K, Osabe D, Shinohara S, Mizumori O, Katashima R, Iwasaki S, Nishimura K, Yoshino M, Kobori M, Ichiishi E, Nakamura N, Yoshikawa T, Tanahashi T, Keshavarz P, Kunika K, Moritani M, Kudo E, Tsugawa K, Takata Y, Hamada D, Yasui N, Miyamoto T, Shiota H, Inoue H, Itakura M (2006) Association of single-nucleotide polymorphisms in the suppressor of cytokine signaling 2 (SOCS2) gene with type 2 diabetes in the Japanese. Genomics 87:446-458

Kim S, Sohn I, Ahn J-I, Lee K-H, Lee YS, Lee YS (2004) Hepatic gene expression profiles in a long-term high-fat diet-induced obesity mouse model. Gene 340:99-109

Kleemann R, van Erk M, Verschuren L, van den Hoek AM, Koek M, Wielinga PY, Jie A, Pellis L, Bobeldijk-Pastorova I, Kelder T, Toet $\mathrm{K}$, Wopereis S, Cnubben N, Evelo C, van Ommen B, Kooistra T (2010) Time-resolved and tissue-specific systems analysis of the pathogenesis of insulin resistance. PLoS ONE 5:e8817

Le Martelot G, Claudel T, Gatfield D, Schaad O, Kornmann B, Sasso GL, Moschetta A, Schibler U (2009) REV-ERBalpha participates in circadian SREBP signaling and bile acid homeostasis. PLoS Biol 7:e1000181

Li JZ, Ye J, Xue B, Qi J, Zhang J, Zhou Z, Li Q, Wen Z, Li P (2007) Cideb regulates diet-induced obesity, liver steatosis, and insulin 
sensitivity by controlling lipogenesis and fatty acid oxidation. Diabetes 56:2523-2532

Libby P (2001) Current concepts of the pathogenesis of the acute coronary syndromes. Circulation 104:365-372

Lydatakis H, Hager IP, Kostadelou E, Mpousmpoulas S, Pappas S, Diamantis I (2006) Non-invasive markers to predict the liver fibrosis in non-alcoholic fatty liver disease. Liver Int 26:864-871

Matsuda Y, Yamagiwa Y, Fukushima K, Ueno Y, Shimosegawa T (2008) Expression of galectin-3 involved in prognosis of patients with hepatocellular carcinoma. Hepatol Res 38:1098-1111

Matsuzawa N, Takamura T, Kurita S, Misu H, Ota T, Ando H, Yokoyama M, Honda M, Zen Y, Nakanuma Y, Miyamoto K-I, Kaneko S (2007) Lipid-induced oxidative stress causes steatohepatitis in mice fed an atherogenic diet. Hepatology 46:1392-1403

Merlin J, Stechly L, de Beaucé S, Monté D, Leteurtre E, van Seuningen I, Huet G, Pigny P (2011) Galectin-3 regulates MUC1 and EGFR cellular distribution and EGFR downstream pathways in pancreatic cancer cells. Oncogene 30:2514-2525

Norwood VF, Morham SG, Smithies O (2000) Postnatal development and progression of renal dysplasia in cyclooxygenase-2 null mice. Kidney Int 58:2291-2300

Ogasawara M, Hirose A, Ono M, Aritake K, Nozaki Y, Takahashi M, Okamoto N, Sakamoto S, Iwasaki S, Asanuma T, Taniguchi T, Urade Y, Onishi S, Saibara T, Oben JA (2011) A novel and comprehensive mouse model of human non-alcoholic steatohepatitis with the full range of dysmetabolic and histological abnormalities induced by gold thioglucose and a high-fat diet. Liver Int 31:542-551

Radonjic M, de Haan JR, van Erk MJ, van Dijk KW, van den Berg SAA, de Groot PJ, Müller M, van Ommen B (2009) Genomewide mRNA expression analysis of hepatic adaptation to high-fat diets reveals switch from an inflammatory to steatotic transcriptional program. PLoS ONE 4:e6646

Roncon-Albuquerque R Jr, Moreira-Rodrigues M, Faria B, Ferreira AP, Cerqueira C, Lourenço AP, Pestana M, von Hafe P, LeiteMoreira AF (2008) Attenuation of the cardiovascular and metabolic complications of obesity in CD14 knockout mice. Life Sci 83:502-510

Seki E, De Minicis S, Osterreicher CH, Kluwe J, Osawa Y, Brenner DA, Schwabe RF (2007) TLR4 enhances TGF-beta signaling and hepatic fibrosis. Nat Med 13:1324-1332

Shannon P, Markiel A, Ozier O, Baliga NS, Wang JT, Ramage D, Amin N, Schwikowski B, Ideker T (2003) Cytoscape: a software environment for integrated models of biomolecular interaction networks. Genome Res 13:2498-2504
Shechter I, Dai P, Huo L, Guan G (2003) IDH1 gene transcription is sterol regulated and activated by SREBP-1a and SREBP-2 in human hepatoma HepG2 cells: evidence that IDH1 may regulate lipogenesis in hepatic cells. J Lipid Res 44:2169-2180

Sheng MH-C, Wergedal JE, Mohan S, Lau K-HW (2008) Osteoactivin is a novel osteoclastic protein and plays a key role in osteoclast differentiation and activity. FEBS Lett 582:1451-1458

Smyth GK (2005) Bioinformatics an computational biology solutions using R an bioconductor. Springer, New York, pp 397-420

Starska K, Brys M, Forma E, Glowacka E, Lewy-Trenda I, Stasikowska O, Krajewska WM, Lukomski M (2009) Impact of EGFR immunoexpression on STAT3 activation and association with proinflammatory/regulatory cytokine pattern in laryngeal squamous cell carcinoma. Oncol Rep 21:539-548

Strazzullo P, D'Elia L, Cairella G, Garbagnati F, Cappuccio FP, Scalfi L (2010) Excess body weight and incidence of stroke: metaanalysis of prospective studies with 2 million participants. Stroke 41:e418-e426

Virbasius JV, Scarpulla RC (1994) Activation of the human mitochondrial transcription factor A gene by nuclear respiratory factors: a potential regulatory link between nuclear and mitochondrial gene expression in organelle biogenesis. Proc Natl Acad Sci USA 91:1309-1313

Virbasius JV, Virbasius CA, Scarpulla RC (1993) Identity of GABP with NRF-2, a multisubunit activator of cytochrome oxidase expression, reveals a cellular role for an ETS domain activator of viral promoters. Genes Dev 7:380-392

Wang YC, McPherson K, Marsh T, Gortmaker SL, Brown M (2011) Health and economic burden of the projected obesity trends in the USA and the UK. Lancet 378:815-825

Yang X, Zhang B, Molony C, Chudin E, Hao K, Zhu J, Gaedigk A, Suver C, Zhong H, Leeder JS, Guengerich FP, Strom SC, Schuetz E, Rushmore TH, Ulrich RG, Slatter JG, Schadt EE, Kasarskis A, Lum PY (2010) Systematic genetic and genomic analysis of cytochrome P450 enzyme activities in human liver. Genome Res 20:1020-1036

Zhang YJ, Jiang W, Chen CJ, Lee CS, Kahn SM, Santella RM, Weinstein IB (1993) Amplification and overexpression of cyclin D1 in human hepatocellular carcinoma. Biochem Biophys Res Commun 196:1010-1016

Zhou Z, Yon Toh S, Chen Z, Guo K, Ng CP, Ponniah S, Lin S-C, Hong W, Li P (2003) Cidea-deficient mice have lean phenotype and are resistant to obesity. Nat Genet 35:49-56 